\title{
Aplikasi Bengkel Motor Dengan Sistem Pakar Menggunakan Metode Forward Chaining
}

\author{
Dzikry Ahmad Fauzy ${ }^{[1]^{*}}$, Iskandar ${ }^{[2]}$, Jepry Rahmadhan ${ }^{[3]}$, Rinto Priambodo ${ }^{[4]}$ \\ Fakultas Ilmu Komputer Program Studi Sistem Informasi ${ }^{[1], ~[2], ~[3], ~[4] ~}$ \\ Universitas Mercu Buana \\ Jakarta Barat, Indonesia \\ 41815120072@student.mercubuna.ac.id ${ }^{[1]}$,41815120095@student.mercubuan.ac.id ${ }^{[2]}$, \\ 41815120122@student.mercubuana.ac.id ${ }^{[3]}$, rinto.priambodo@mercubuana.ac.id ${ }^{[4]}$
}

\begin{abstract}
Motorcycle is an important transportation tool in its activities, especially in the Jakarta area which is famous for its traffic jams. By using a motorcycle, the trip becomes more efficient. Therefore motorcycles need maintenance so that the condition of the motorcycle remains good and prime. However, not all motorcycle users know the damage. My Workshop application makes it easy for customers to repair, service, sell parts and take care of motorbikes, from periodic maintenance to repairing damaged motorbikes by bringing mechanics directly to the customer's home or location (Home Service). My Workshop application makes it easy for customers to diagnose motorcycle damage using the Forward Chaining method which refers to the knowledge of experts or called Expert Systems. With Forward Chaining reasoning techniques, detection is done by starting from a series of symptom questions and then being able to see conclusions about the type of damage to the motorcycle. With this method customers can find out damage to motor vehicles before coming to the garage or consulting a mechanic. In this study there are several categories obtained from official workshops, namely machinery, electricity, cogs, ignition. Of the four categories raises the question of damage that is often experienced by customers. Therefore, the authors make the data as a repair shop application system, which is used to diagnose damage.
\end{abstract}

\section{Keywords - Workshop, Forward Chaining, Expert System}

Abstrak - Sepeda motor adalah sarana transportasi yang penting dalam beraktifitas khususnya di daerah Jakarta yang terkenal kemacetannya. Dengan menggunakan sepeda motor perjalanan yang ditempuh lebih efisien. Maka dari itu sepeda motor membutuhkan perawatan agar kondisi motor tetap baik dan prima. Namun demikian tidak semua pengguna sepeda motor mengetahui kerusakan yang dialami. Aplikasi Bengkel Ku memudahkan pelanggan dalam reparasi, jasa servis, penjualan sparepart dan perawatan sepeda motor, mulai dari perawatan berkala sampai servis kerusakan sepeda motor dengan mendatangkan mekanik langsung ke rumah atau lokasi pelanggan (Home Service). Aplikasi Bengkel Ku memudahkan pelanggan mendiagnosis kerusakan sepeda motor dengan menggunakan metode Forward Chaining yang mengacu pada pengetahuan para ahli atau disebut Sistem Pakar. Dengan teknik penalaran Forward Chaining, deteksi dilakukan dengan memulai dari sekumpulan pertanyaan gejala nantinya dapat melihat kesimpulan jenis kerusakan pada sepeda motor. Dengan metode ini pelanggan dapat mengetahui kerusakan kendaraan sepeda motor sebelum datang ke bengkel atau berkonsultasi kepada mekanik. Dalam penelitian ini ada beberapa kategori yang di dapatkan dari bengkel resmi yaitu mesin, kelistrikan, penggerak roda, pengapian. Dari keempat kategori tersebut menumbulkan pertanyan pertanyaan kerusakan yang sering dialami pelanggan. Maka dari itu penulis menjadikan data tersebut sebagai pembuatan sistem aplikasi bengkel, yang digunakan untuk mendiagnosis kerusakan.

\section{Kata Kunci-Bengkel, Forward Chaining, Sistem Pakar}

\section{PENDAHULUAN}

Kendaraan sepeda motor semakin bertambah jumlahnya, Setiap orang memiliki sepeda motor pribadi yang berbeda-beda dan setiap pemilik sepeda motor perlu melakukan pemeliharaan. Para produsen selalu menyarankan agar pemeliharaan dilakukan rutin di bengkel resmi masing-masing. Masalah yang dialami saat ini adalah keterbatasan informasi mengenai kerusakan sepeda motor masih membingungkan, terlebih lagi bagi pengguna sepeda motor yang tidak memiliki pengetahuan mengenai jenis-jenis kerusakan pada sepeda motor. Situasi seperti inilah yang menjadi dasar dalam penelitian ini untuk membuat sebuah perangkat lunak yang bisa membantu pemilik sepeda motor untuk mendiagnosis kerusakan. Sehingga dari hasil penelitian ini dapat dihasilkan sebuah perangkat lunak berupa Aplikasi Bengkel Motor Dengan Sistem Pakar Menggunakan Metode Forward Chaining. Forward Chaining adalah strategi untuk memulai proses pencarian data atau fakta, data-data tersebut dijadikan suatu kesimpulan dan solusi dari permasalahan yang dihadapi. Dimana dengan menggunakan aplikasi ini pengguna dapat mendiagnosis kerusakan sepeda motor dan juga bisa melakukan penjadwalan servis untuk mekanik dapat langsung datang ke rumah.

\section{TINJUAN PUSTAKA}

\section{A. Bengkel}

Bengkel memiliki arti tempat yang digunakan untuk memperbaiki sepeda, mobil dan sebagainya. Dimulai dari transaksi pembelian penjualan spare part, pengolahan data customer, pelayanan servis, hingga mendiagnosis kerusakan. Sehingga memperbaiki dan meningkatkan efisiensi kerja. [1] 


\section{B. Artificial Intelligence (AI)}

Artificial Intelligence (AI) adalah sebuah sistem atau mesin yang mampu berfikir dan menimbang permasalahan agar dapat diselesaikan dengan baik. Kecerdasan buatan dapat dijadikan suatu pengambilan keputusan berdasarkan data-data yang telah diolah oleh sistem kecerdasan buatan ini. kecerdasan buatan menjadi salah satu bagian ilmu komputer yang dapat mempelajari bagaimana membuat sistem komputer yang mampu berfikir seperti manusia yang dapat menganalisis berbagai permasalahan.[2][3][4]

\section{Sistem Pakar}

Sistem Pakar merupakan ilmu kecerdasan buatan yang dapat membantu pengguna untuk memecahkan masalah di bidang kerusakan, berdasarkan informasi yang berisi sekumpulan pengetahuan pakar dan bisa digunakan untuk berkonsultasi tentang gejala gejala sampai kepada kesimpulan sehingga dapat menjawab semua permasalahan yang ada.[5][6][7]

\section{Metode forward Chaining}

Metode Forward Chaining dilakukan dengan cara menganalisa kerusakan dengan rumus runtut ke depan dengan mengunakan rumus (jika) dan (maka). Oleh karena itu peneliti menjadikan metode forward chaining sebagai metode diagnosis dimana terdapat beberapa pertanyaan untuk menanyakan gejala yang timbul pada sepeda motor sehingga dapat diambil keputusan bahwa dibagian apa yang sedang mengalami kerusakan. Penerapan metode ini mengacu pada informasi informasi yang di dapat dari seorang ahli atau pakar. Di lain sisi metode forward chaining juga membantu mekanik dalam menyelesaikan permasalahan kerusakan mesin sepeda motor.[8][9]

\section{METODE PENELITIAN}

\section{A. Penelitian Terdahulu}

Penelitian yang berkaitan dengan penggunaan Forward Chaining sudah banyak dilakukan, salah satunya penelitian dari Implementasi Metode Dempster-Shafer Pada Sistem Pakar Pendiagnosa Kerusakan Sepeda Motor. Penelitian ini menerapkan Metode Dempster-Shafer untuk mengatasi ketidakpastian yang terjadi pada Sistem Pakar Pendiagnosa Kerusakan Sepeda Motor Yamaha, sehingga pengguna sistem pakar dapat mengetahui seberapa besar nilai keyakinan suatu kerusakan dialami oleh sebuah sepeda motor. Hal ini membantu pengguna memutuskan tindakan apa yang harus dilakukan terhadap sepeda motornya. Nilai densitas yang digunakan dalam penelitian ini berasal dari pakar, sehingga memungkinkan nilainya berbeda antara pakar yang satu dengan yang lain.[10] Penelitian lain tentang forward chaining adalah penelitian yang berjudul Sistem Pakar Diagnosa Kerusakan Mesin Sepeda Motor Transmission Automatic dengan Metode Forward Chaining. Penelitian ini menerapkan metode forward chaining dapat digunakan sebagai penambah pengetahuan tentang mesin sepeda motor matic dari gejala-gejala yang dialami, memudahkan pengguna yang kurang memahami mesin motor, sehingga dapat tepat dalam menangani kerusakan yang ada, Proses diagnosis yang dilakukan melalui aplikasi dapat dilakukan dengan cepat sehingga memangkas waktu yang sebelumnya banyak terbuang di bengkel dan aplikasi ini dirancang dengan tampilan yang user friendly untuk memudahkan user dalam pengoperasiannya.[11] Penelitian selanjutnya yang berhubungan dengan forward chaining adalah Aplikasi Diagnosis Kerusakan Sepeda Motor Bebek Metode Forward Chaining Berbasis Android. Dari hasil penelitiannya Sistem yang telah dibangun dapat mendiagnosis gejala kerusakan pada kendaraan sepeda motor bebek. Serta memberikan informasi tentang jenis kerusakan, penyebab dan solusi kerusakan dengan mudah.[12] Penelitian selanjutnya berjudul Sistem Pakar Diagnosa kerusakan sepeda motor matic injeksi menggunakan metode forward chaining berbasis android. Penelitian ini mempunyai kelebihan untuk membantu para pengguna motor matic injeksi untuk mengetahui kerusakan motor matic injeksi berdasarkan gejala - gejala yang ada.[13] Penelitian lain yang berkaitan dengan forward chaining adalah Sistem Pakar Deteksi Kerusakan Sepeda Motor dengan Metode Forward Chaining. Penelitian ini menghasilkan pendeteksian kerusakan sepeda motor automatic dapat menolong pengguna untuk mengetahui kerusakan kendaraannya dan mendapat petunjuk singkat bagaimana memperbaikinya. Kualitas sebuah sistem pakar sangat bergantung kepada kualitas dari pengetahuan pakar yang dapat direpresentasikan kedalam basis pengetahuannya. Penelitian ini mengambil contoh kasus kerusakan pada sepeda motor automatic.[14]

\section{B. Tahap Perancangan Sistem}

Pada gambar 1 merupakan penjelasan tahap- tahap pada penelitian ini, yaitu: (1) Tahap perumusan masalah, (2) Tahap analisa dan perancangan (3) Tahap implementasi dan pengujian.

Tahap pertama yaitu perumusan masalah. Pada tahap ini dilakukan identifikasi masalah dengan mewawancarai kepala bengkel dan mekanik. Identifikasi masalah juga dilakukan melalui studi pustaka dengan mencari refrensi pada jurnaljurnal, buku-buku, dan karya ilmiah yang berhubungan dengan kerusakan mesin. Selanjutnya melakukan analisis dari hasil identifikasi masalah untuk menentukan tujuan dan ruang lingkup penelitian.

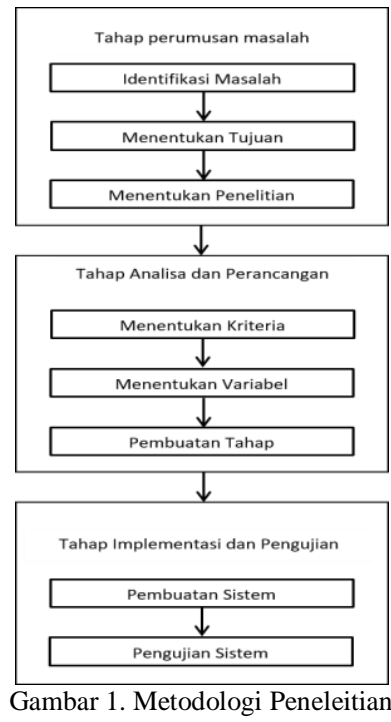


Pada Gambar 1 Tahap kedua yaitu analisa dan perancangan. Pada tahap ini pengumpulan data untuk memperkuat informasi yang telah didapatkan sebelumnya. Pada gambar 2 merupakan data kerusakan sepeda motor yang paling banyak dan paling sedikit terjadi di sebuah bengkel resmi. Data tersebut dijadikan variabel jenis kerusakan pada penelitian ini.

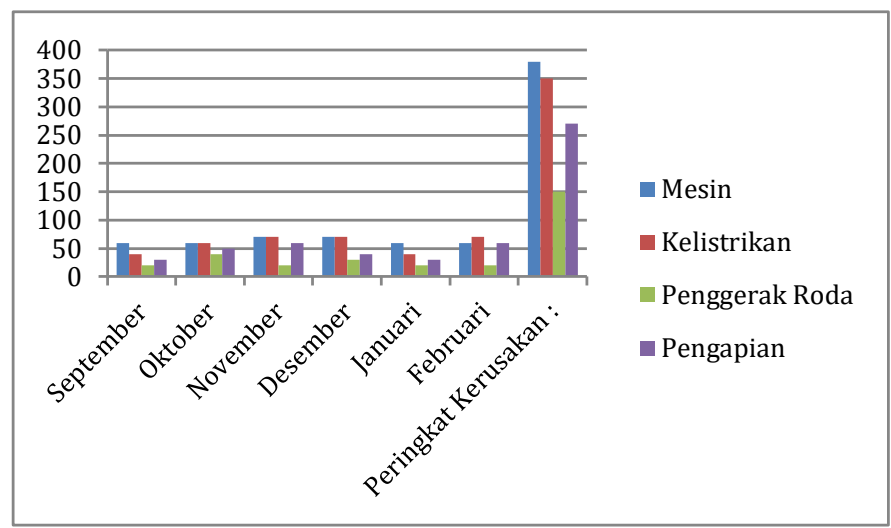

Gambar 2. Data Kerusakan

Gambar 2 merupakan hasil dari data bengkel resmi yang menjelaskan total kerusakan terbanyak dan sedikit perbulan September 2019 hinga Januari 2020. Kerusakan dari mesin sebanyak 380 kasus, kelistrikan 350 kasus, pengepian 270 kasus dan penggerak roda 150 kasus. Kesimpulannya kerusakan mesin paling banyak dan kerusakan penggerak roda paling sedikit terjadi.

Setelah menganalisa variabel-variabel yang dibutuhkan sesuai dengan kriteria kriteria yang dihasilkan. Hal terakhir adalah merancang aturan-aturan (rule) yang dibutuhkan sistem pakar ini.

Tahap terakhir adalah implementasi dan pengujian. Pada tahap ini dibuat sistem pakar yang mengacu pada aturan-aturan yang telah dibuat pada tahap kedua. Selanjutnya melakukan pengujian terhadap sistem. Ada 2 pengujian yaitu: Uji fungsionalitas dan Uji validalitas.

\section{Analisis Sistem Berjalan}

Metode PIECES digunakan untuk menaganalisis sistem yang berjalan di bengkel sebelum aplikasi di buat. Dalam analisis ini di lakukan enam eveluasi menggunakan enam variabel yaitu performance, information, economy, control, efficiency, service.

\section{1) Kinerja (Peformance)}

Mendiagnosa keruskan para pengguna sepeda motor masih mengunakan proses manual yang belum tentu kebenaran nya tentang kerusakan yang di alami dengan mengunakan system diagnosa maka proses penanganan kerusakan akan relatif mudah di selesaikan.

2) Informasi (Information)

Akses informasi tentang kerusakan terkadang mejadi masalah bagi pengguna sepeda motor dengan adanya sistem diagnosis maka informasi tentang kerusakan akan lebih mudah di ketahui dengan konkrit dan jelas.

3) Ekonomi (Economy)

Masih perlu nya konsulatasi dengan mekanik untuk mengetahui tentang kerusakan kenadaraan sepeda motor sehingga pelanggan masih perlu adanya biaya lain untuk hanya mengetahui kerusakan kenadraan nya yang di luar perkiraan awalnya.

4) Keamanan/Kontrol (Control)

Keamanan diagnosa di sistem ini sangat baik karena data data yang di peroleh berasal dari para ahli di bidang nya sehingga informasi kerusakan dapat di percaya.

5) Efisiensi (Efficiency)

Lebih menghemat waktu untuk mengetahui kerusakan kenadaraan sepeda motor sehingga pengguna hanya mengakses system diagnosa dimana pun dan kapan pun hanya bermodalkan koneksi internet.

6) Pelayanan (Service)

Tahap mengetahui kerusakan yang dialami pelanggan memakan waktu cukup lama, pelanggan harus datang ke bengkel untuk berkonsultasi dengan mekanik.

\section{Metode Pengembangan Sistem Forward Chaining}

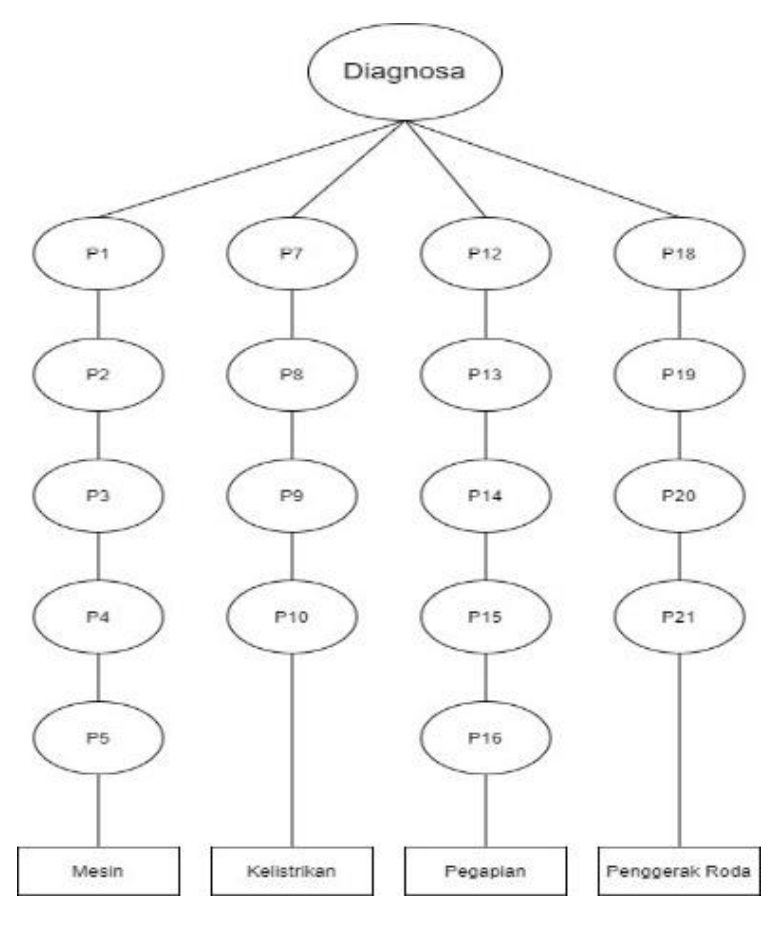

Gambar 3. Proses Forward Chaining

Gambar 3 merupakan pohon penelusuran kerusakan, menjelaskan suatu sistem pakar untuk mendiagnosa kerusakan pada sepeda motor.

Dalam sistem pakar yang menggunakan metode kaidah Forward Chaining yang ditulis dengan menggunakan rumus "Jika dan Maka". Tahap-tahap yang akan ditulis tersebut adalah : 


\begin{tabular}{|l|}
\hline Tahap 1 \\
JIKA suara mesin kasar \\
DAN mesin susah nyala \\
DAN terdengar kasar pada bagian mesin \\
DAN pada saat di gas suara mesin kasar dan \\
menimbulkan getaran \\
DAN terdapat kebocoran oli pada bagian mesin \\
MAKA kerusakan pada mesin \\
Tahap 2 \\
JIKA aki cepat habis atau drop \\
DAN kabel lampu cepat putus \\
DAN kabel stater mati \\
DAN motor mati total \\
MAKA kerusakan Pada Kelistrikan \\
Tahap 3 \\
JIKA motor tidak bisa di starter \\
DAN busi masih memercikan api \\
DAN koil terputus atau lepas dari \\
DAN CDI konslet \\
DAN sepul megalami kerusakan \\
MAKA kerusakan Pada Bagian Pengapian \\
Tahap 4 \\
JIKA terdengar suara berisik pada bagian kiri bawah mesin \\
DAN terdengar suara kasar pada saat motor jalan \\
DAKA kerusakan Pada Bagian Penggerak Roda \\
\hline
\end{tabular}

\section{PEMBAHASAN}

\section{A. Pemodelan Sistem}

\section{1) Diagram Alir}

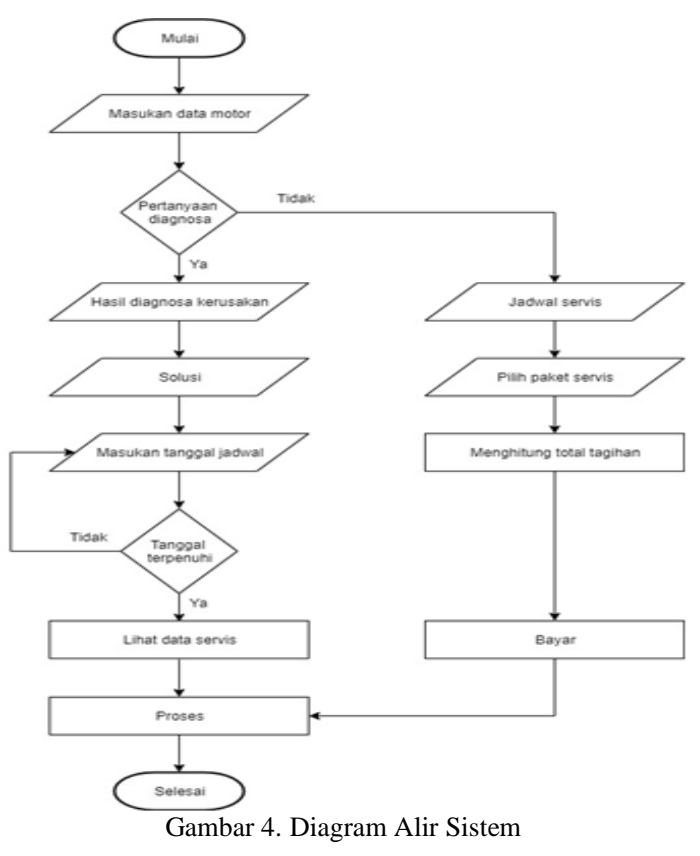

Gambar 4 merupakan Diagram Alir Sistem, penelitian ini akan menghasilkan sebuah sistem atau aplikasi baru yang berbasis web. Aplikasi ini juga dapat mendiagnosis kerusakan pada sepeda motor dengan cara menjawab pertanyaan sesuai dengan kendala-kendala yang dialami pengguna sepeda motor.

2) Use Case Diagram

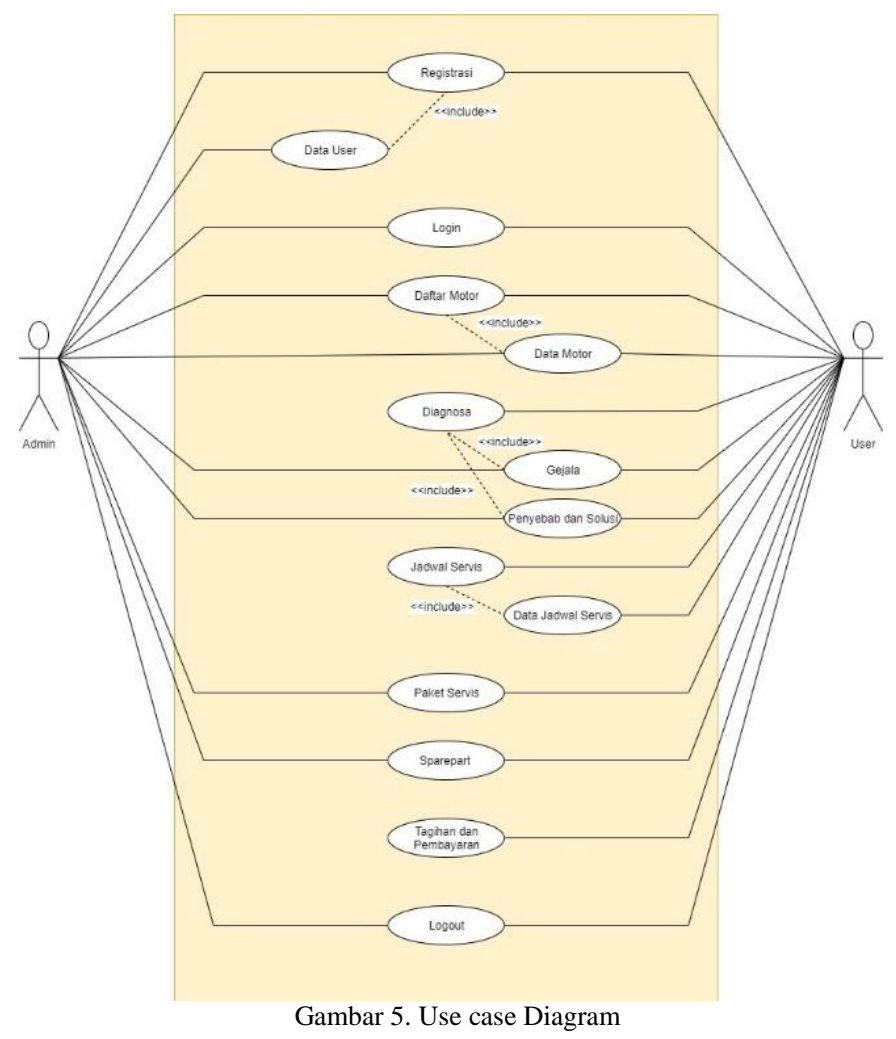

Gambar 5 merupakan use case Aplikasi yang akan dibuat, Aplikasi ini memiliki dua aktor mulai dari pengguna untuk masuk dengan mendaftarkan usernamenya untuk menjadi login pengguna, setelah berhasil masuk maka pengguna dapat menggunakan semua fitur yang ada di Aplikasi ini.

Aplikasi ini dapat melakukan Pemesanan penjadwal servis serta dapat mendiagnosis kerusakan sepeda motor, sistem yang berjalan di admin dapat melihat semua pemesanan penjadwal dan dapat mengubah pertayaan-pertayaan diagnosis agar dapat mengetahui kerusakan pada sepeda motor pengguna yang datadatanya didapatkan dari para narasumber.

3) Activity Diagram 


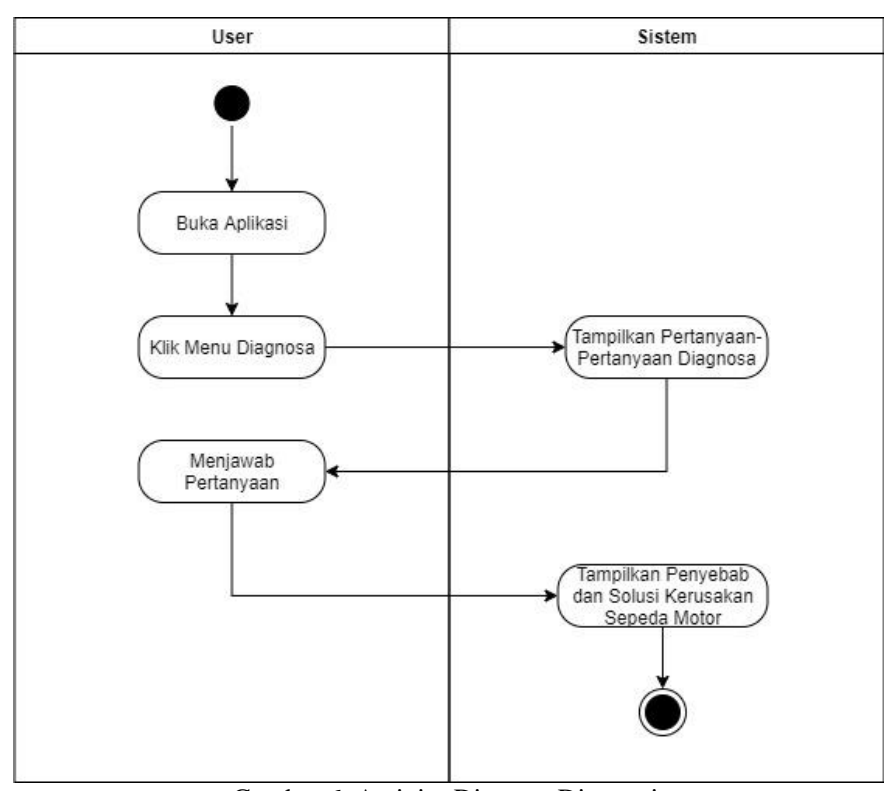

Gambar 6. Activity Diagram Diagnosis

Gambar 6 merupakan Activity Diagram diagnosis menjelaskan tentang caranya untuk menggunakan fitur diagnosis dari aplikasi yang akan dibuat penjelasannya adalah sebagai berikut:

Pengguna membuka aplikasi untuk memulai dan masuk menggunakan username dan kata sandi yang terdaftar sebelumnya, Pengguna membuka fitur diagnosis, sistem menampilkan pertayaan pertayaan seputar gejala gejala pengguna, pengguna harus menjawab semua pertanyaan yang disediakan sistem sesuai dengan gejala-gejala yang di alami, Sistem akan menampilkan permasalahan yang di alami pengguna.

\section{4) Sequence Diagram}

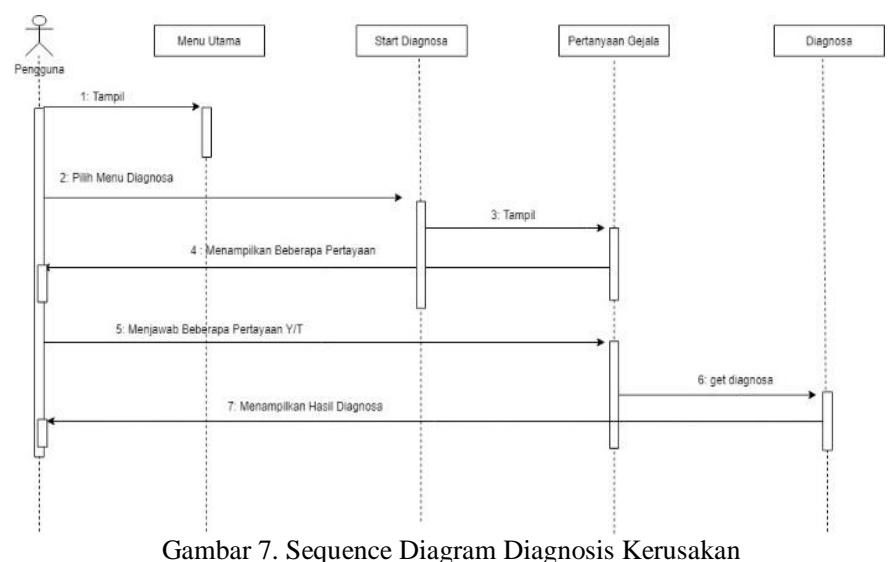

Gambar 7 merupakan sequence diagram Diagnosa kerusakan adalah diagram diagnosa pada user. Terdapat beberapa tahapan awal dalam melakukan diagnosa adapun penjelasannya sebagai berikut:

pengguna membuka aplikasi untuk memulai.

pengguna memilih menu diagnosa pengguna menjawab semua pertayaan pertayaan yang disediakan sistem

pengguna membaca kerusakan yang di alami.

\section{5) Entity Diagram}

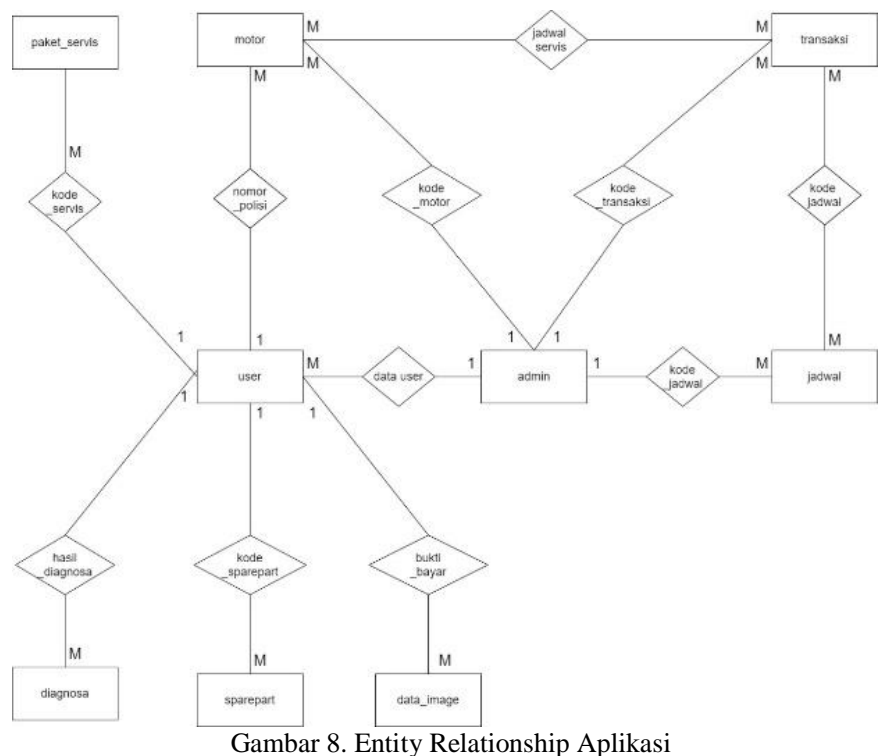

\section{B. Diagnosis Kerusakan Menggunakan Metode Forward Chaining}

TABEL I. DATA KERUSAKAN

\begin{tabular}{|c|l|l|}
\hline No & Kode kerusakan & Nama Kerusakan \\
\hline 1 & K1 & Kerusakan Mesin \\
\hline 2 & K2 & Kerusakan Kelistrikan \\
\hline 3 & K3 & Kerusakan Pengapian \\
\hline 4 & K4 & Kerusakan Penggerak Roda \\
\hline
\end{tabular}

Tabel 1 Menampilkan data kerusakan berupa jenis kerusakan yang menjelaskan tetang bagian kerusakan pada sepeda motor pengguna. Jenis kerusakan ini didapatkan dari hasil wawancara langsung dengan kepala bengkel yang menjadi narasumber dalam penelitian ini.

TABEL II ATURAN MENENTUKAN JENIS KERUSAKAN

\begin{tabular}{|c|l|l|c|c|c|c|}
\hline \multirow{2}{*}{ NO } & \multirow{2}{*}{ Gejala } & \multirow{2}{*}{ Penjelasan } & \multicolumn{3}{|c|}{ Kode Kerusakan } \\
\cline { 4 - 7 } & & K1 & K2 & K3 & K4 \\
\hline 1 & P1 & Suara mesin kasar & 1 & & & \\
\hline 2 & P2 & Mesin susah nyala & 1 & & & \\
\hline 3 & P3 & $\begin{array}{l}\text { Terdengar kasar } \\
\text { pada bagian mesin }\end{array}$ & 1 & & & \\
\hline 4 & P4 & $\begin{array}{l}\text { Pada saat di gas } \\
\text { suara mesin kasar } \\
\text { dan menimbulkan } \\
\text { getaran }\end{array}$ & 1 & & & \\
\hline 5 & P5 & Terdapat & 1 & & & \\
\hline
\end{tabular}




\begin{tabular}{|c|c|c|c|c|c|c|}
\hline \multirow{2}{*}{ NO } & \multirow{2}{*}{ Gejala } & \multirow{2}{*}{ Penjelasan } & \multicolumn{4}{|c|}{ Kode Kerusakan } \\
\hline & & & K1 & K2 & K3 & K4 \\
\hline & & $\begin{array}{l}\text { kebocoran oli pada } \\
\text { bagian mesin }\end{array}$ & & & & \\
\hline 7 & $\mathrm{P} 7$ & $\begin{array}{l}\text { Aki cepat habis } \\
\text { atau drop }\end{array}$ & & 1 & & \\
\hline 8 & P8 & $\begin{array}{l}\text { Kabel lampu cepat } \\
\text { putus }\end{array}$ & & 1 & & \\
\hline 9 & $\mathrm{P} 9$ & Kabel stater mati & & 1 & & \\
\hline 10 & $\mathrm{P} 10$ & Motor mati total & & 1 & & \\
\hline 11 & $\mathrm{P} 12$ & $\begin{array}{l}\text { Motor tidak bisa } \\
\text { di starter }\end{array}$ & & & 1 & \\
\hline 12 & P13 & $\begin{array}{l}\text { Busi masih } \\
\text { memercikan api }\end{array}$ & & & 1 & \\
\hline 13 & P14 & $\begin{array}{l}\text { Koil terputus atau } \\
\text { lepas dari sepul } \\
\text { pengapian }\end{array}$ & & & 1 & \\
\hline 14 & P16 & CDI konslet & & & 1 & \\
\hline 15 & P17 & $\begin{array}{l}\text { Sepul megalami } \\
\text { kerusakan }\end{array}$ & & & 1 & \\
\hline 16 & $\mathrm{P} 18$ & $\begin{array}{l}\text { Terdengar suara } \\
\text { berisik pada } \\
\text { bagian kiri bawah } \\
\text { mesin }\end{array}$ & & & & 1 \\
\hline 17 & P19 & $\begin{array}{l}\text { Terdengar suara } \\
\text { kasar pada saat } \\
\text { motor jalan }\end{array}$ & & & & 1 \\
\hline 18 & $\mathrm{P} 20$ & Roda Tidak stabil & & & & 1 \\
\hline 19 & $\mathrm{P} 21$ & Ban kurang angina & & & & 1 \\
\hline
\end{tabular}

Tabel 2 merupakan aturan-aturan untuk menentukan jenis kerusakan berdasarkan gejala-gejala yang ada pada aturan forward chaining yang digambarkan dengan tabel menggunakan rumus jika-maka sehingga dapat mempermudah dalam pembuatan sistem diagnosis kerusakan pada sepeda motor.

\section{Iterasi}

Iterasi dalam forward chaining merupakan proses tindakan atau pembagian aturan yang terpisah di ambil dari gejala-gejala kerusakan yang di alami pengguna sepeda motor. Proses tindakan di bagi menjadi empat kali proses sesuai dengan jenis kerusakan yang ada pada Tabel 1 .

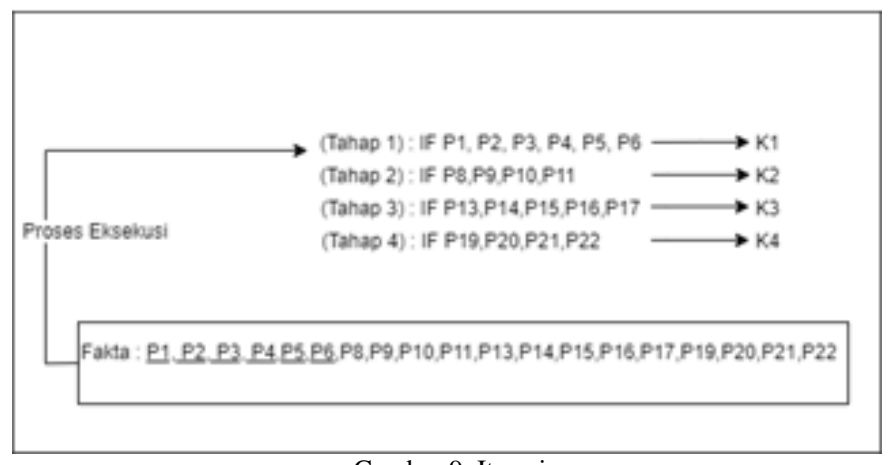

Gambar 9. Iterasi

Gambar 9 proses tindakan di lakukan untuk menemukan fakta baru yang berkaitan dengan kerusakan pada mepsin pengguna sepeda motor. fakta yang di temukan adalah : K1

Tahap 1 = P1,P2,P3,P4,P5,P6 dari tahap 1 menghasilkan

Tahap 2 = P8,P9,P10,P11 dari tahap 2 menghasilkan K2 K3

Tahap 3 = P13,P14,P15,P16,P17 dari tahap 3 menghasilkan

Tahap 4 = P19,P20,P21,P22 dari tahap 4 menghasilkan K4

dari keempat proses tersebut didapat fakta baru. Yang digunakan dalam diagnosis kerusakan sepeda motor.

\section{Tampilan Sistem}
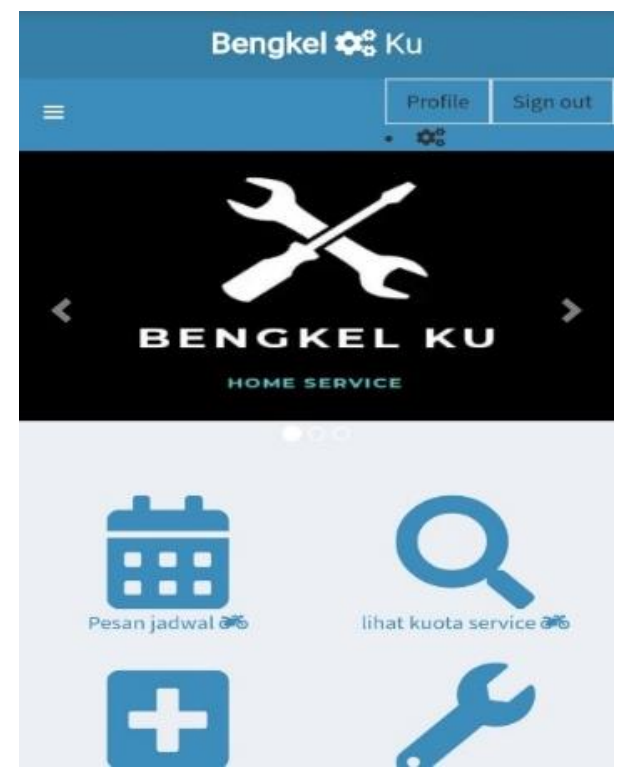

Gambar 10. Tampilan Utama

Gambar 10 merupakan tampilan utama aplikasi yang berbasis mobile web. Pada tampilan ini pengguna dapat mengakses modul yang tersedia seperti tambah motor, jadwal servis, paket servis, sparepart. Modul lainya adalah pengguna dapat mendiagnosa kerusakan motor dengan cara menjawab semua pertanyaan mengenai gejala-gejala yang dialami pengguna. Maka setelah pertayaan-pertanyaan pengguna dapat mengetahui bagian mana yang rusak pada sepeda motor.

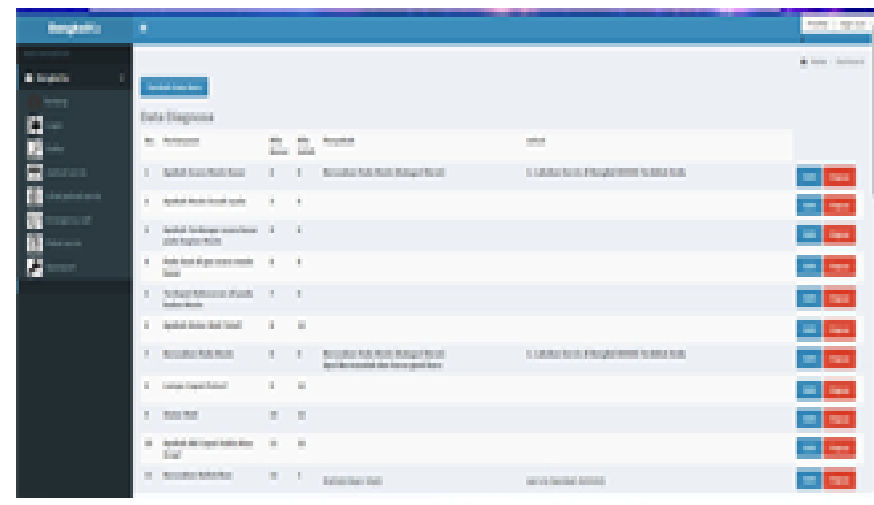

Gambar 11. Tambahan Pertanyaan Diagnosis 
Gambar 11 merupakan fitur penambahan pertanyaan untuk sistem diagnosis kerusakan sepeda motor sehingga jika ada kerusakan-kerusakan lain yang belum dimasukan ke dalam sistem. Admin dapat menambahkannya dengan cara sebagai berikut:

1. Admin mencatat semua gejala, penyebab, serta solusi berdasarkan hasil wawancara dengan mekanik

2. Admin akan menginput semua jenis kerusakan pada motor pada sistem yang sedang di bangun.

3. Admin membuat pertanyaan seputar gejala gejala yang ditimbulkan oleh sepeda motor rusak dan di relasikan penyebab dan solusi yang harus di lakukan oleh pengguna sepeda motor.

Sitem menampilakan data detail kerusakan yang telah dilalui dengan pertanyaan di atas.

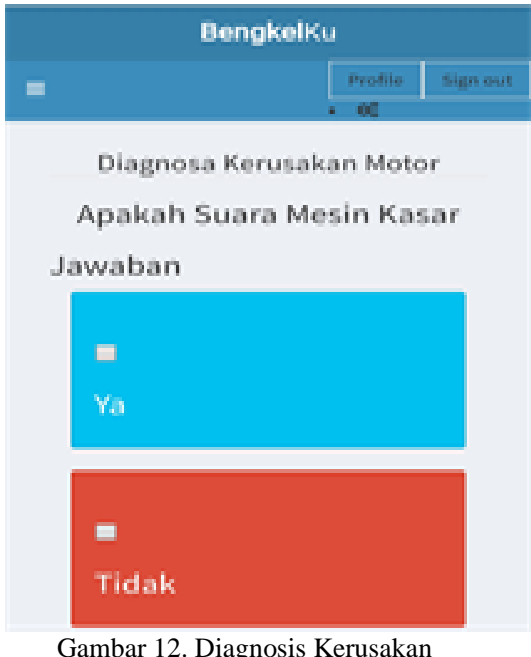

Gambar 12 merupakan menu diagnosis kerusakan sepeda motor dimana pengguna sepeda motor dapat melakukan mengecekan kerusakan pada kendaraan nya dengan cara menjawab pertanyaan-pertanyaan yang disediakan.
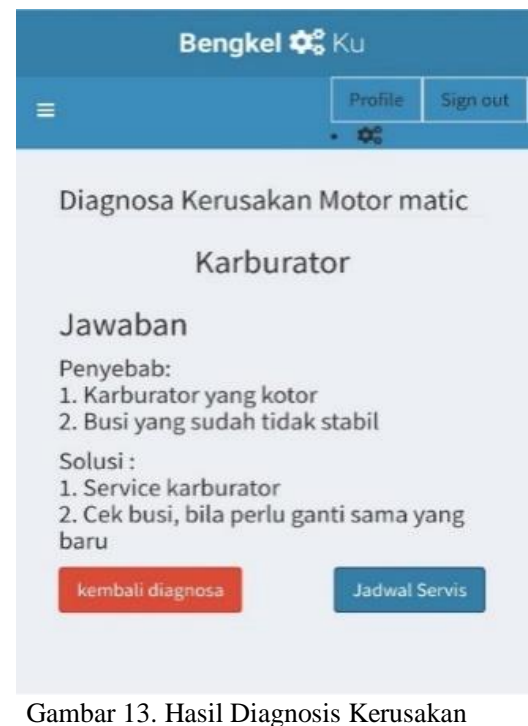

Gambar 13. Hasil Diagnosis Kerusakan
Gambar 13 merupakan hasil diagnosis kerusakan setelah Pengguna menjawab semua pertayaan yang di sediakan sistem maka sistem akan menampilkan hasil dari diagnosis keruskan sesuai dengan gelaja gejala yang di alami pengguna sepeda motor.Gambar 13 Diagnosis Kerusakan.

\section{E. Pengujian Sistem}

Pengujian mengunakan metode black box testing. Skenario yang diusulkan pengembang aplikasi adalah untuk menjawab semua pertanyaan yang disediakan oleh sistem sesuai dengan gejala yang dialami kendaraannya. Hasil yang diharapkan sistem ini dapat menjawab pertanyaan dan menampilkan detail kerusakan yang dialami.

Testing yang dilakukan oleh kepala bengkel telah sesuai dangan kebutuhan. Fitur yang telah di validasi diantara nya adalah:

Fitur diagnosis pada aplikasi ini digunakan sebagai mendiagnosis kerusakan kendaraan sepeda motor. Diagnosa menurut kepala bengkel fitur ini sangat membantu pekerjaan mekanik menjadi lebih mudah.

\begin{tabular}{|c|c|c|c|}
\hline \multicolumn{4}{|c|}{ Pengisisian datta diegnosa } \\
\hline \multirow{2}{*}{\multicolumn{4}{|c|}{ Hasil Pengujjan (Data Normal) }} \\
\hline & & & $\begin{array}{l}\text { Kesimpulan } \\
\end{array}$ \\
\hline Tambah Data & $\begin{array}{l}\text { Data masuk pada server database } \\
\text { datatabase }\end{array}$ & Data masuk pada seever databasese & $\begin{array}{l}{[x] \text { Diterima }} \\
[]] \text { Ditolak }\end{array}$ \\
\hline Ubah Data & Data dapat diubah dan datata pada severer dattabase diubah & Data pada server datäbasse dapat diubah & $\mid \begin{array}{l}{\left[\begin{array}{l}{[x] \text { Diterima }} \\
{[1] \text { Ditolak }}\end{array}\right.} \\
\end{array}$ \\
\hline Hapus Dota & Data user dapat dihapus den data padd server ddtabase terhapus & Dota user pada server database terhbopus & $\mid\left[\begin{array}{l}{[x] \text { Diterima }} \\
{[1] \text { Ditolak }}\end{array} \mid\right.$ \\
\hline \multicolumn{4}{|c|}{$\begin{array}{c}\text { rengIsian data alagrosasa } \\
\text { sil Penguvian (Data Salah) }\end{array}$} \\
\hline Data Masukan & Tampilan & Pengamatan & Kesimpulan \\
\hline Data tidak terisi leneka & Ada pemberitahuan bahwa pengisian tidak lengkap & Muncul pemberitahuan bahwa pengisian data & 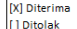 \\
\hline
\end{tabular}

\section{PENUTUP}

Berdasarkan Hasil penelitian yang di lakukan metode forward chaining dapat di jadikan acuan untuk mendiagnosa kerusakan kendaraan sepeda motor. Metode forward chaining dapat di lakukan dengan tiga tahap. Tahap pertama pengumpulan informasi mengenai gejala gejala yang akan timbul dan wawancara para teknisi di bengkel resmi. Tahap kedua perancangan rule rule mengunakan kaidah forward chaining. Tahap ketiga implemetasi system aplikasi bengkel dengan system pakar menggunakan metode forward chaining dari hasil evaluasi menunjukan bahwa diagnosa pada kendaraan sepeda motor sangat bermanfaat dan tingkat akurasi system mencapai $70 \%$ dengan menggunakan 30 data uji coba dalam aplikasi ini belum tersedia nya rekapan penjualan sparepart sehingga perlu di kembangkan kembali.

\section{DAFTAR PUSTAKA}

[1] Y. S. Wahyu Novianto, "Analisa dan perancangan sistem informasi bengkel pada bengkel lancar motor," Idealis, vol. 1, no. Vol 1 No 5 (2018): Jurnal IDEALIS November 2018, pp. 57-63, 2018.

[2] H. D. Hutahaean, "Penerapan Metode Case Based Reasoning Dalam Mengidentifikasi Kerusakan Kamera Dslr," J. Mantik Penusa, vol. 20, no. Jurnal Mantik Penusa Volume 20 No 1 Desember 2016 ISSN 20883943, pp. 87-90, 2016.

[3] D. Ayuningsih and N. A. Hasibuan, "Sistem Pakar Mendiagnosa Kerusakan Pada Mesin Penggilingan Padi Menggunakan Metode Naive 
Bayes," J. JURIKOM (Jurnal Ris. Komputer), vol. 5, no. 4, pp. 371-376, 2018.

[4] R. Sumintena, "Sistem Pakar Diagnosa Kerusakan Laptop Menggunakan Metode Forward Chaining Sumintena," J. Resti, vol. 2, no. 3, pp. 604 $610,2018$.

[5] M. Hadi, M.Misdram, and R. F. Aini, "PERANCANGAN SISTEM PAKAR DIAGNOSA PENYAKIT AYAM DENGAN METODE FORWARD CHAINING," J. Inform. Merdeka Pasuruan, vol. 2, no. 1, p. $29,2016$.

[6] I. Akil, "Analisa Efektifitas Metode Forward Chaining Dan Backward Chaining Pada Sistem Pakar," J. Pilar Nusa Mandiri, vol. 13, no. 1, pp. 35-42, 2017.

[7] A. H. Jamal, "Sistem Pakar Membedakan Islam Syiah dan Islam Sunni Berbasis WEB," J. Tek. Inform., vol. 2617, no. 1, 2019.

[8] S. Pratama and R. Priambodo, "Data Warehouse Menggunakan Algoritma Naïve Bayes Untuk Menunjang Analisis Divisi Marketing Di Perusahaan Multifinance," J. Cendikia, vol. XVII, no. April, 2019.

[9] A. H. Radia Afnur, Titi Sriwahyuni, "Rancang bangun aplikasi sistem pakar untuk diagnosis kerusakan sepeda motor matic menggunakan metode forward chaining," Voteknika, vol. 4, no. 2, pp. 75-84, 2016.

[10] S. Iswanti and R. N. Anggraeny, "Implementasi Metode DempsterShafer Pada Sistem Pakar Pendiagnosa Kerusakan Sepeda Motor,"
Inform. Mulawarman J. Ilm. Ilmu Komput., vol. 14, no. 1, p. 38, 2019, doi: 10.30872/jim.v14i1.1443.

[11] I. Imron, M. N. Afidah, M. S. Nurhayati, S. Sulistiyah, and F. Fatmawati, "Sistem Pakar Diagnosa Kerusakan Mesin Sepeda Motor Transmission Automatic dengan Metode Forward Chaining Studi Kasus: AHASS 00955 Mitra Perdana,” J. Ilm. Univ. Batanghari Jambi, vol. 19, no. 3, p. 544, 2019, doi: 10.33087/jiubj.v19i3.742.

[12] T. P. Mardiko, "APLIKASI DIAGNOSIS KERUSAKAN SEPEDA MOTOR BEBEK METODE FORWARD CHAINING BERBASIS ANDROID," J. Ilm. Univ. Batanghari Jambi, vol. 19, 2019.

[13] A. Sartika Wiguna and I. Harianto, "SISTEM PAKAR DIAGNOSA KERUSAKAN SEPEDA MOTOR MATIC INJEKSI MENGGUNAKAN METODE FORWARD CHAINING BERBASIS ANDROID," SMARTICS J., vol. 3, no. 1, pp. 25-30, 2017.

[14] D. Alfrido and T. K. Gautama, "Sistem Pakar Deteksi Kerusakan Sepeda Motor dengan Metode Forward Chaining," J. Tek. Inform. dan Sist. Inf., vol. 3, no. 3, pp. 618-636, 2017, doi: 10.28932/jutisi.v3i3.705. 